\title{
A CROSS-SECTIONAL SERODIAGNOSTIC SURVEY OF CANINE LEISHMANIASIS DUE TO LEISHMANIA CHAGASI
}

\author{
MOACIR PARANHOS-SILVA, LUIS A. R. FREITAS, WASHINGTON C. SANTOS, \\ GABRIEL GRIMALDI JR., LAIN C. PONTES-DE-CARVALHO, AND \\ ANTONIO J. OLIVEIRA-DOS-SANTOS \\ Centro de Pesquisas Goncalo Moniz, Fundacao Oswaldo Cruz, Salvador, Brazil; Instituto de \\ Ciencias da Saude, Universidade Federal da Bahia, Salvador, Brazil; Departamento de Imunologia, \\ Instituto Oswaldo Cruz, Fundacao Oswaldo Cruz, Rio de Janeiro, Brazil
}

\begin{abstract}
Jequie, a community of about 144,500 inhabitants located in the State of Bahia, Brazil, is endemic for both visceral and cutaneous leishmaniases. In the present epidemiologic study, the urban and inhabited periurban areas of the town were divided into 140 clusters of $0.25 \mathrm{~km}^{2}$ each. The seroprevalence of canine Leishmania antibodies was investigated using an enzyme-linked immunosorbent assay as a screening test since its sensitivity was significantly higher than that of an indirect immunofluorescence assay. A total of 1,681 dogs was surveyed in 34 randomly sampled clusters. The overall prevalence of Leishmania antibodies in the dog population was $23.5 \%$, with intracluster prevalences ranging from $0 \%$ to $67 \%$. There was no correlation of these seroprevalences with the intracluster densities of canine populations, or with the distances from individual clusters to the town center. Moreover, the Leishmania transmission did not seem to follow any clear-cut spatial pattern, since large disparities in the seroprevalences of contiguous clusters were found. Curiously, human cases of visceral leishmaniasis have never been observed in some clusters with a relatively high prevalence of canine seroprevalences. Eight parasite isolates from seropositive dogs were found to belong to the same serodeme and zymodeme as Leishmania (L.) chagasi. The implications of these findings with respect to the epidemiology and control of American visceral leishmaniasis are discussed.
\end{abstract}

American visceral leishmaniasis (AVL) is usually caused by Leishmania $(L$.) chagasi, which is transmitted by the sand fly Lutzomyia longipalpis. Domestic dogs and foxes are presumed to be the major vertebrate reservoirs of the parasite., 2 The infection is endemic in many areas of Central and South America, and the disease typically affects undernourished children due to a compromised immune system. ${ }^{3}$ More than 90\% of AVL cases reported in the New World have occurred in Brazil, ${ }^{4}$ where a total of 20,191 cases was recorded before $1990 .^{5}$ From the public health viewpoint, the most important epidemiologic aspects of AVL in Brazil are that the number of reported cases is increasing 5,6 and new foci are continually emerging. ?

The importance of ecologic and demographic changes in the natural sylvatic cycle of $L$. chagasi has been emphasized. Since the insect vector can adapt to altered environments, the epidemiology of AVL also changes. ${ }^{8}$ It is believed that when infected foxes (Cerdocyon thous and Lycalopex vetulus) come to feed near human dwellings, they are bitten by $L u$. longipalpis living in the peridomestic environment. These sand flies then become infected and subsequently transmit the parasite to dogs or humans living nearby. ${ }^{1,8}$ In theory, it should be possible to virtually eradicate AVL by interrupting the peridomestic transmission cycle. However, this has not happened with the current control methods when applied to old endemic foci. ${ }^{9}$ These results indicate that our knowledge of the ecology and epidemiology of AVL is incomplete and that new control strategies are needed.

Some of us have previously documented that the town of Jequie, State of Bahia, Brazil, is an endemic focus for both visceral and cutaneous leishmaniases. ${ }^{10}$ In this area, $L u$. longipalpis has been found both in and around houses (Sherlock 1, unpublished data). The diseases are geographically distributed in the following manner: patients with cutaneous leishmaniasis live and/or work in rural areas near a forest, while patients with visceral disease live predominantly in an urban area. ${ }^{10}$ Infected dogs were also found in Jequie. ${ }^{11}$ These findings prompted us to study the epidemiology of canine visceral disease in the town of Jequie.

The goal of the present work was to investigate the seroprevalence of, and to identify the Leishmania species responsible for, canine leishmaniases in Jequie. Furthermore, an enzyme-linked immunosorbent assay (ELISA) and an indirect immunofluorescence assay (IFA) were compared as screening tests for Leishmania antibodies.

\section{MATERIALS AND METHODS}

Area. Jequie municipality, with a surface area of 3,113 $\mathrm{km}^{2}$, is situated at $13^{\circ} 52^{\prime} \mathrm{S}$ and $40^{\circ} 4^{\prime} \mathrm{W}, 112 \mathrm{~km}$ from the Atlantic Ocean and $216 \mathrm{~m}$ above sea level. It is a region with a semi-arid tropical climate, with an annual average temperature of $24^{\circ} \mathrm{C}$ and rainfall of $50 \mathrm{~cm}$ yearly. The natural predominant vegetation consists of small deciduous trees, shrubs, cactus, and grasses. However, some rural areas of the municipality are covered by tropical rain forest or secondary woodland, with rainfall of between 70 and $100 \mathrm{~cm}$ a year. The population was 144,572 inhabitants in 1991, of which approximately $21 \%$ live in rural areas. The urban and periurban inhabited areas of the town were divided in 140 clusters of $0.25 \mathrm{~km}^{2}$ (Figure 1).

Animals. The sera of seven dogs experimentally infected with Leishmania ${ }^{12}$ and of 39 dogs naturally infected, all with parasitologically positive bone marrow or spleen aspirates, were used in a study to compare the ELISA and IFA. The sera of 102 healthy dogs (domiciled in an area nonendemic for leishmaniases) were used as negative controls.

In the present survey, we used the single-stage cluster sampling technique for selection of a sample from the dog population to estimate the proportion (P) of anti-Leishmania seropositive dogs. ${ }^{13}$ The clusters were of unequal size (in terms of population) and a sample was drawn by the single random method. In each selected sector, all domiciled dogs 


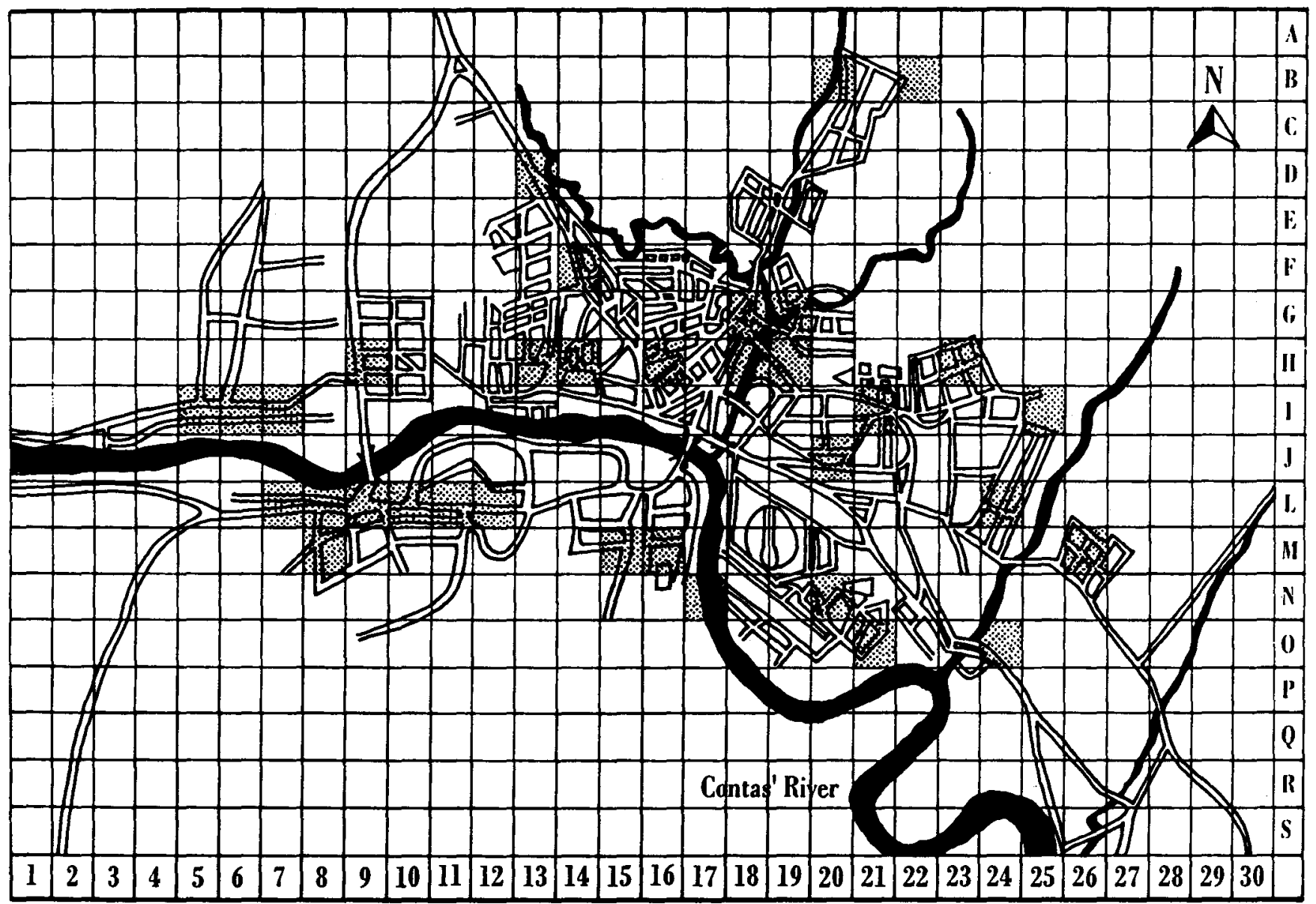

FIGURE 1. Urban and periurban areas of the town of Jequie, State of Bahia, Brazil. The dotted areas represent the sample clusters.

were listed and a venous blood sample was collected, with verbal agreement of the animal owners. Serum samples were stored at $-20^{\circ} \mathrm{C}$ for later analyses. A total of 1,681 dogs was included in the present study, covering a period from May to December 1991.

Serologic assays. The ELISA was carried out as described by Voltler and others ${ }^{14}$ using microtiter plate wells coated with a soluble extract of $L$. chagasi promastigotes, sera of dogs diluted 1:400, and a 1:5,000 dilution of goat anti-dog immunoglobulin G (IgG)-peroxidase conjugate (Sigma Chemical Co., St. Louis, MO). Positive and negative control sera were included in each assay. The ELISA results from control animals had a normal frequency distribution (Kolmogorov-Smirnov normality test $\mathrm{d}=0.217, P<0.01$ and Lilliefors $P<0.01$ ). Values greater than the mean plus three standard deviation values of the results obtained from 102 healthy dogs were considered positive. All sera were tested in duplicate and those yielding positive results were retested at least once.

The IFA was carried out as described by Evans and others ${ }^{9}$ using $L$. mexicana promastigotes adsorbed to microscope slides, sera of dogs diluted 1:40-1:320, and a 1:80 dilution of goat anti-dog IgG-fluorescein conjugate (Sigma Chemical Co.). Positive and negative control sera were tested on each slide.

Parasite isolates. During the epidemiologic survey in Je- quie, a total of 50 Leishmania isolates were obtained from seropositive dogs. The primary isolation was made by culture of a sample obtained by aspiration of spleen and/or bone marrow, using NNN medium containing an overlay of modified liquid liver infusion tryptose medium and incubated at $25^{\circ} \mathrm{C}$. ${ }^{15}$ Two weeks later, each isolate was transferred to Schneider's Drosophila medium supplemented with 20\% heat-inactivated fetal calf serum and maintained at $24^{\circ} \mathrm{C} .{ }^{16}$

Eight parasite isolates from the dogs (stock codes: MCAN/BR/91/755; MCAN/BR/91/1194; MCAN/BR/91/ 1373; MCAN/BR/91/1439; MCAN/BR/91/1486; MCAN/ BR/92/578; MCAN/BR/92/1036; MCAN/BR/92/1075) were typed by monoclonal antibodies and/or enzyme electrophoresis analyses. ${ }^{17}$

Statistical analysis. For comparison of specificities and sensitivities of serologic screening assays, the McNemar test was used and $95 \%$ confidence intervals (CIs) were calculated using the normal distribution for proportion. The Leishmania antibody levels from experimentally and naturally infected dogs were compared by the nonparametric Wald-Wolfowitz runs test. The $\chi^{2}$ distribution fitness was used for analysis of cluster seroprevalence differences, while seroprevalence differences among sex subsets were compared by the $\chi^{2}$ test. $^{18}$ The correlation between cluster seroprevalences and canine population densities was tested by linear regression. ${ }^{19}$ 

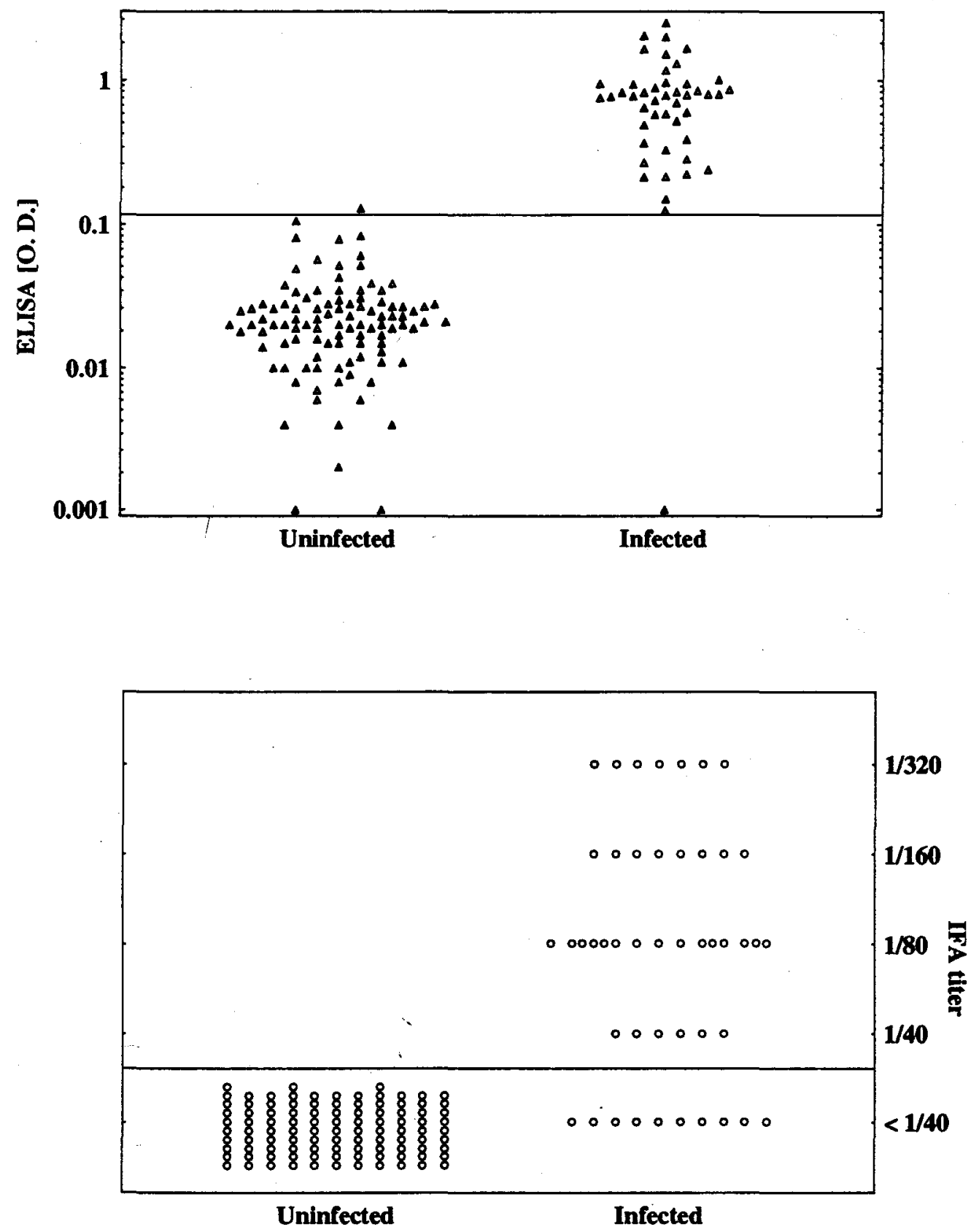

FIGURE 2. Results of enzyme-linked immunosorbent assay (ELISA) and indirect immunofluorescence assay (IFA) for Leishmania antibodies in the sera of 46 infected and 102 healthy dogs in Jequie, Brazil. Infection was ascertained by the isolation of Leishmania parasites from bone marrow and/or spleen. The solid horizontal lines represent the cutoff values for each method. O.D. = optical density.

For calculation of the proportion p, i.e., an unbiased estimate of $\mathbf{P}$ (proportion of seropositive dogs in the population), the following formula was used:

$$
\underset{\alpha=1}{\mathbf{p}} \sum_{\alpha=1}^{c} n_{i \alpha} / \sum \mathbf{n}_{\alpha}
$$

where $n_{i a}=$ total number of seropositive dogs in the $\alpha^{\text {th }}$ sample cluster, $n_{\alpha}=$ total number of dogs living in the $\alpha^{\text {th }}$ sample cluster, and $c=$ total number of sample clusters. Its variance is:

$$
S^{2}=\frac{1-f}{c \cdot \bar{M}^{2} \cdot(C-1)} \sum_{\alpha=1}^{c}\left(n \alpha^{2} \cdot(P \alpha-p)^{2}\right)
$$

where $C=$ total of inhabited clusters, $f=c / C=$ sample fraction among the clusters, $\bar{M}=\Sigma_{\alpha=1}^{c} n \alpha / c=$ average cluster size, and $\mathrm{P \alpha}=$ proportion of seropositive dogs in the ath sample cluster.

\section{RESULTS}

Comparison between ELISA and IFA. The levels of Leishmania antibodies in the sera of 102 healthy dogs and 
TABLE 1

Comparison of enzyme-linked immunosorbent assay (ELISA) and indirect immunofluorescence assay (IFA) as screening tests for canine leshmaniases

\begin{tabular}{|c|c|c|c|c|}
\hline \multirow[b]{3}{*}{ Samples } & \multicolumn{2}{|c|}{ ELISA } & \multicolumn{2}{|c|}{ IFA } \\
\hline & Negative & Positive & Negative & Positive \\
\hline & No. (\%) & No. (\%) & No. (\%) & No. (\%) \\
\hline $\begin{array}{l}\text { Uninfected } \\
(n=102)\end{array}$ & $101(99)$ & $1(1)$ & $102(100)$ & $0(0)$ \\
\hline $\begin{array}{l}\text { Infected } \\
(n=46)\end{array}$ & $1(2)$ & $45(98)$ & $10(22)$ & $36(78)$ \\
\hline
\end{tabular}

46 dogs with proven Leishmania infection, as detected by ELISA and IFA methods, are shown in Figure 2. The specificities were $99 \%(95 \% \mathrm{CI}=97-101 \%)$ and $100 \%$, respectively, for ELISA and IFA (Table 1). This difference was not statistically significant $(P=1.0$, by McNemar test). On the other hand, while the ELISA recognized 45 of 46 infected dogs, only 36 of them were positive by IFA. These results correspond to sensitivities of $78 \%(95 \% \mathrm{CI}=66-90 \%)$ and 98\% (95\% CI $=94-102 \%)$ for the IFA and ELISA, respectively (Table 1). This difference in sensitivity was statistically significant $(P=0.0077$, by McNemar test). The serum negative in the ELISA was also negative in the IFA. There was no significant correlation between serum titers by IFA and the strengths of reactions in the ELISA $(r=0.54, P>$ 0.05 ). In addition, no statistically significant differences in Leishmania antibody levels of experimental and of naturally infected dogs were observed $(P=0.83$, by Wald-Wolfowitz runs test).

Seroprevalence. The sera from 395 of 1,681 dogs (923 males and 758 females) were positive for Leishmania antibodies when tested by ELISA (Table 2). This corresponded to a Leishmania infection seroprevalence of $23.5 \%$ (95\% CI $=22-25 \%$ ). There were no differences in sex distribution between the infected and noninfected dog subsets $(P>0.05$, by $\chi^{2}$ test). The seroprevalences through town clusters ranged from $0 \%$ to $67 \%$ (Table 2), suggesting a large heterogeneity in the transmission of Leishmania within the canine population of the town $\left(P<0.001\right.$, by $x^{2}$ frequency distribution). Furthermore, the seroprevalence was not related to the distance from the town center, with the main central cluster $(16-\mathrm{H})$ showing an infection rate of $28 \%$. When the canine population density among each sample cluster was analyzed, no correlation with seroprevalence was detected (r $=-0.25, P>0.05$ ).

Parasite identification. Eight Leishmania isolates from seropositive dogs were identified as $L$. chagasi by their pattern of reactivity with species-specific monoclonal antibodies and/or by enzyme electrophoresis analyses.

\section{DISCUSSION}

The emergence of AVL as an increasingly important public health problem in tropical America appears to be due to different factors. The massive destruction of primary forests, together with rapid human population growth and the concomitant development of new farmland and rural settlements, have led to conditions that support large populations of Lu. longipalpis. ${ }^{8}$ New migrants typically settle in hastily
TABLE 2

Seroprevalence of canine Leishmania infection in clusters of the town of Jequie, state of Bahia, Brazil, as determined by enzymelinked immunosorbent assay

\begin{tabular}{|c|c|c|c|}
\hline \multirow[b]{2}{*}{$\begin{array}{l}\text { Sample } \\
\text { cluster }\end{array}$} & \multicolumn{2}{|c|}{ Dog sera } & \multirow[b]{2}{*}{$\begin{array}{l}\text { Population } \\
\text { density }\end{array}$} \\
\hline & $\begin{array}{l}\text { No. positive/ } \\
\text { no. tested }\end{array}$ & \% positive & \\
\hline 5-I & $15 / 32$ & 47 & 178 \\
\hline 6-I & $1 / 24$ & 4 & 96 \\
\hline $7-I$ & $12 / 49$ & 24 & 196 \\
\hline $7-\mathrm{L}$ & $12 / 49$ & 24 & 196 \\
\hline $8-\mathrm{L}$ & $20 / 38$ & 53 & 157 \\
\hline $8-\mathbf{M}$ & $6 / 11$ & 55 & 44 \\
\hline 9-H & $5 / 22$ & 23 & 88 \\
\hline 9-L & $10 / 28$ & 36 & 112 \\
\hline $10-\mathrm{L}$ & $22 / 52$ & 42 & 208 \\
\hline $11-\mathrm{L}$ & $12 / 52$ & 23 & 208 \\
\hline $12-\mathrm{L}$ & $0 / 8$ & 0 & 32 \\
\hline $13-\bar{D}$ & $9 / 27$ & 33 & 108 \\
\hline 13-H & $30 / 102$ & 29 & 408 \\
\hline $14-F$ & $36 / 162$ & 22 & 648 \\
\hline 14-H & $21 / 94$ & 22 & 376 \\
\hline $15-M$ & $11 / 59$ & 19 & 236 \\
\hline $16-H$ & $17 / 61$ & 28 & 244 \\
\hline $16-M$ & $11 / 84$ & 13 & 336 \\
\hline $17-N$ & $21 / 68$ & 31 & 272 \\
\hline $18-G$ & $4 / 41$ & 10 & 164 \\
\hline $18-H$ & $5 / 42$ & 12 & 168 \\
\hline $19-G$ & $11 / 67$ & 16 & 268 \\
\hline $19-\mathrm{H}$ & $3 / 63$ & 5 & 252 \\
\hline $20-B$ & $1 / 3$ & 33 & 12 \\
\hline 20-J & $20 / 138$ & 14 & 552 \\
\hline $20-N$ & $22 / 77$ & 29 & 308 \\
\hline $21-I$ & $17 / 86$ & 20 & 384 \\
\hline $21-0$ & $10 / 40$ & 25 & 168 \\
\hline $22-B$ & $4 / 16$ & 25 & 64 \\
\hline $23-\mathrm{H}$ & $3 / 22$ & 14 & 88 \\
\hline $24-\mathrm{L}$ & $11 / 21$ & 52 & 84 \\
\hline 24-O & $6 / 22$ & 27 & 88 \\
\hline 25-I & $3 / 15$ & 20 & 60 \\
\hline $26-M$ & $4 / 6$ & 67 & 24 \\
\hline Total & $395 / 1.681$ & 23.5 & 197 \\
\hline
\end{tabular}

* No. of dogs $\mathrm{km}^{2}$.

constructed shanty towns on the periphery of large cities, which are overcrowded and have inadequate housing and poor sanitation. Many of the new migrants bring with them dogs, chickens, and pigs, which they keep in or around their houses. These conditions create an excellent habitat for vectors, and the density of these insects in both houses and animal shelters may reach very high levels., 8, 20 As a consequence, AVL has recently begun to appear in periurban areas of major Brazilian cities such as Fortaleza, ${ }^{21} \mathrm{Natal}^{7}$ Sao Luis, ${ }^{22}$ Terezina, ${ }^{6}$ and Rio de Janeiro, ${ }^{5}$ where dogs alone seem to be the major reservoir of the parasite.

Although control of AVL has been achieved in some areas by 1) diagnosis and treatment of human cases, 2) elimination of infected dogs, and 3) vector control, these methods require constant vigilance to be effective. ${ }^{23,24}$ As a consequence, the relative ineffectiveness of these control measures represents another factor contributing to the increasing relevance of AVL as a public health problem in Brazil.9 Furthermore, $L$. chagasi infection in dogs is not uniformly lethal. ${ }^{25,26}$ The studies referred to above suggest that 1 ) subclinical infections with $L$. chagasi may occur commonly in dogs, as they do in humans;27 2) some dogs may develop 
immunity or resistance to leishmanial reinfections; and 3) destruction of all infected (seropositive) dogs in a community may be unnecessary and perhaps even unwise, since some of the animals will spontaneously recover and may actually become immune.

In the present paper, an ELISA and IFA were compared as screening tests for canine Leishmania infections. Their sensitivities were $98 \%$ and $78 \%$, respectively, with similar specificities (approximately 100\%) for both methods. The better performance of the ELISA agrees with the results obtained by Evans and others, ${ }^{9}$ who showed that of 405 dogs tested in northeast Brazil, $17 \%$ were positive by IFA and $38 \%$ were positive by ELISA. The latter test, therefore, should be preferred over the IFA for the identification of infected dogs, and was used in the canine seroprevalence study described here.

The seroprevalence study showed a general rate of $23.5 \%$ $(95 \% \mathrm{CI}=22-25 \%)$, indicating that canine infection is more frequent than human visceral leishmaniasis in this endemic area: a three-year accumulated incidence of 130 human cases per 100,000 inhabitants was observed during roughly the same time period in this area. ${ }^{10}$ This agrees with the report of Alencar, ${ }^{28}$ who suggested that the infection of dogs with Leishmania occurs more frequently than human disease in Brazilian endemic areas. In the present study, all seropositive dogs were killed as recommended by the Brazilian National Health Foundation.

We did not find any correlation between canine population density and cluster seroprevalence, which argues against an important effect of host population density on Leishmania transmission. Furthermore, the heterogeneity in the seroprevalences of different town clusters did not indicate any spatial pattern of Leishmania transmission among dogs in the town, with seroprevalence varying in contiguous sectors from $47 \%$ to $4 \%$ (for instance, clusters 5-1 and 6-1, Figure 1). These observations agree with those of Jaffe and others, ${ }^{29}$ who when studying an endemic focus in northern Israel, found $10 \%$ of the dogs with canine leishmaniasis in contrast to another village (1.6 km away), where none of the 24 dogs examined was infected.

A total of eight isolates were identified as $L$ chagasi, the only species found among dogs in the Jequie area until now. Since both visceral and cutaneous leishmaniases occur in the study area ${ }^{10}$ (although the second is predominantly a rural disease), we can not exclude the possibility that some of the dogs were also infected with Leishmania species other than L. chagasi.

The Brazilian federal government program for controlling visceral leishmaniasis in Jequie relies on the painless killing of dogs that have Leishmania antibodies and on spraying with DDT the area located within a $500-\mathrm{m}$ radius of reported human AVL cases. The program started in 1991 resulted in the examination of approximately 4,000 dogs per year, but it has not had a clear-cut effect on the incidence of human AVL, which varied from 42 cases in Jequie in 1992, eight in 1993, 23 in 1994, and 70 in the first six months of 1995. The present paper adduces two reasons for these results that do not completely invalidate the program rationale. First, the screening test used was the IFA. As shown herein and elsewhere, ${ }^{9}$ this assay is much less sensitive than the ELISA, and may have missed up to $34 \%$ of the infected dogs.
Second, only dogs living in clusters where human cases had been previously reported were included in the program. In Jequie, this means about one-third of the total canine population. The present data, however, indicate a much more extensive spreading of canine infection in the town. In fact, dogs with Leishmania antibodies were found in 33 of the 34 clusters studied (Table 2). In some of these clusters, no human AVL case had been reported. These dogs, not included in the official control program, could be contributing to the dissemination of the infection, both within the town and to other districts. In fact, migration of dogs between different areas of Jequie has been observed (Paranhos-Silva $\mathbf{M}$ and others, unpublished data).

It is clear, therefore, that to conclusively assess the impact of the elimination of infected dogs on the incidence of human AVL, all infected dogs in the studied area should be killed. The identification of areas with canine infection to be subsequently included in a program for AVL control, or in a study aiming at evaluating such program, could be easily accomplished by population screenings such as the one described herein, in which just a random sample was studied. This could avoid the wasting of efforts by directing the control procedures to areas directly affected by canine leishmaniasis, and, most importantly, by preventing areas with infected dogs to be neglected by the program or study, since this could seriously compromise the interpretation of results. The present study in which a $14 \%$ sample of the Jequie canine population was studied indicates that virtually all dogs (approximately 12,000 animals) should be screened for Leishmania antibodies. We should point out that a careful cost-effectiveness analysis should be done before such strategy is implemented in any endemic area.

Acknowledgments: This work was carried out as part of the Leishmaniases Project -Jequie, Bahia, in collaboration with the National Health Foundation (Bahia, Brazil), 13th Regional Health Board of Bahia, and the Jequie Municipality Health Board. We are indebted to health agents of the National Health Foundation (Jequie, Bahia, Brazil), whose help was essential in carrying out this study. We are also thankful to Dr. M. A. Nagata for kind assistance in the indirect immunofluorescence assays. Moacir Paranhos-Silva has submitted this work to the Institute of Biological Sciences, Federal Univerșity of Minas Gerais (Brazil) in partial fulfillment of his MSc thesis.

Financial support: This work was partially supported by grants from the Brazilian Research Council (CNPq) and the Oswaldo Cruz Foundation (PAPES/FIOCRUZ). Antonio J. Oliveira-dos-Santos and Washington C. Santos received fellowships from the CNPq.

Authors' addresses: Moacir Paranhos-Silva, Luis A. R. Freitas, Washington C. Santos, and Lain C. Pontes-de-Carvalho, Centro de Pesquisas Goncalo Moniz, Fundacao Oswaldo Cruz, R. Valdemar Falcao, 121, Salvador, BA, 40295-001, Brazil. Gabriel Grimaldi Jr., Departamento de Imunologia, Fundacao Oswaldo Cruz, Av. Brasil, 4365, Rio de Janeiro, RJ, 21045-900, Brazil. Antonio J. Oliveirados-Santos, Institute for General and Experimental Pathology, University of Innsbruck, Medical School, Fritz-Pregl-Strasse 3/IV, A6020 Innsbruck, Austria.

Reprint requests: Antonio J. Oliveira-dos-Santos, Institute for General and Experimental Pathology, University of Innsbruck, Medical School, Fritz-Pregl-Strasse 3/IV, A-6020 Innsbruck, Austria. E-mail. Antonio.Oliveira-dos-Santos@uibk.ac.at.

\section{REFERENCES}

1. Deane LM, Deane MP, 1955 . Observaoes preliminares sobre a importancia comparativa do homem, cao e da raposa (Lycal- 
opex vetulus) como reservatorio de Leishmania donovani em area endemica do calazar, no Ceara. O Hosp (Rio de Janeiro) 48: $61-76$

2. Lainson R, Shaw JJ, 1987. Evolution, classification and geographical distribution. Peters W, Killick-Kendrick R, eds. The Leishmaniases in Biology and Medicine. Volume 1. London: Academic Press, 1-128.

3. Grimaldi G Jr, Tesh RB, McMahon-Pratt D, 1989. A review of the geographic distribution and epidemiology of leishmaniasis in the New World. Am J Trop Med Hyg 41: 687-725.

4. Grimaldi G Jr, Tesh RB, 1993. Leishmaniasis of the New World: current concepts and implications for future research. Clin Microbiol Rev 6: 230-250.

5. Marzoch MSM, Marzoch KBF, Carvalho RW, 1994. Visceral leishmaniasis in Rio de Janeiro. Parasitol Today 10: 37-40.

6. Costa CHN, Pereira HF, Araujo MV, 1990. Epidemia de leishmaniose visceral no estado do Piaui, Brasil, 1980-1986. Rev Saude Publica 24: 361-372.

7. Jeronimo SMB, Oliveira RM, Mackay S, Costa RM, Sweet J, Nascimento ET, Luz KG, Fernandes MZ, Jernigan J, Pearson $R D$, 1994. An urban outbreak of visceral leishmaniasis in Natal, Brazil. Trans $R$ Soc Trop Med Hyg 88: 386-388.

8. Lainson $R, 1989$. Demographic changes and their influence on the epidemiology of American leishmaniasis. Service MW, ed. Demography and Vector-Bome Diseases. Boca Raton, FL: CRC Press, 85-106.

9. Evans TG, Vasconcelos LAB, Lima JW, Teixeira JM, McAullife IT, Lopes UG, Pearson RD, Vasconcelos AW, 1990. Canine visceral leishmaniasis in northeast Brazil: assessment of serodiagnostic methods. Am J Trop Med Hyg 42: 118-123.

10. Oliveira-dos-Santos AJ, Nascimento EG, Paranhos-Silva M, Pontes-de-Carvalho LC, 1993. Report on a visceral and cutaneous leishmaniases focus in the town of Jequie, State of Bahia, Brazil. Rev Inst Med Trop Sao Paulo 35: 583-584.

11. Sherlock IA, Almeida, 1970. Notas sobre leishmaniose canina no Estado da Bahia. Rev Bras Malariol Doencas Trop 22: 231-242.

12. Paranhos M, Santos WC, Sherlock I, Oliveira GGS, Pontes-deCarvalho LC, 1993. Development of eosinophilia in dogs intradermically inoculated with sand fly saliva and Leishmania (Leishmania) chagasi stationary-phase promastigotes. Mem Inst Oswaldo Cruz 88: 249-251.

13. Cochran WG, 1977. Sampling Techniques. Third edition. New York: John Wiley \& Sons, 233-273.

14. Voltler A, Bartlett A, Bidwell DE, 1976. Enzyme immunoassays with special reference to ELISA techniques. J Clin Pathol 31: 507-520.

15. Jaffe CL, Grimaldi G Jr, McMahon-Pratt D, 1984. The culti- vation and cloning of Leishmania. Morel CM, ed. Genes and Antigens of Parasites. A Laboratory Manual. Geneva: UNDP/ World Bank/WHO-FINEP-CPPq-FIOCRUZ, 47-91.

16. Hendricks LD, Wood DE, Hadjuk ME, 1978. Haemollagellates: commercially available liquid media for rapid cultivation. Parasitology 76: 309-316.

17. Grimaldi G Jr, Momem $H$, Naiff RD, McMahon-Pratt D, Barrett TB, 1991. Characterization and classification of leishmanial parasites from humans, wild mammals, and sand flies in the Amazon region, Brazil. Am J Trop Med Hyg 44: 645-661.

18. Cochran WG, 1954. Some methods for strengthening the common $\chi^{2}$ test. Biometrics 10: 417-451.

19. Colton T, 1974. Statistics in Medicine. Boston: Little, Brown and Co., 191-204.

20. Deane LM, Deane MP, 1955. Sobre a biologia do Phlebotomus longipalpis transmissor de leishmaiose visceral, em area endemica do Ceara. I. Distribuicao, predominancia e variacao estacional. Rev Bras Biol 15: 83-95.

21. Vasconcelos IAB, Vasconcelos AW, Momem H, Grimaldi G Jr, Alencar JE, 1988. Epidemiological studies on American leishmaniasis in Ceara State, Brazil. Molecular characterization of Leishmania isolates. Ann Trop Med Parasitol 82: 547-554.

22. Nascimento MDSB, Bandeira KP, Filho MS, Ahid S, BarrosBezerra GF, Castro-Alvin M, Carvalho-Bastos O, ParanhosSilva M, Sadigursky M, 1992. Observacoes preliminares sobre a leishmaniose visceral canina (LVC) na ilha de Sao Luis, MA: aspectos soroepidemiologicos, clinicos e histopatologicos. Rev Soc Bras Med Trop 25 (suppl): 85-86.

23. Alencar JE, 1961. Profilaxia do calazar no Ceara, Brasil. Rev Inst Med Trop Sao Paulo 3: 175-180.

24. WHO/TDR Program, 1991. Leishmaniasis -Progress in Research 1989/1990. Geneva: Tenth Program Report, 79-87.

25. Abranches P, Silva-Pereira MGD, Conceicao-Silva FM, GomesSantos GM, Jany JG, 1991. Canine leishmaniasis: pathological and ecological factors influencing transmission of infection. J Parasitol 77: 557-561.

26. Cabral M, O'Grady J, Alexander J, 1992. Demonstration of Leishmania specific cell mediated and humoral immunity in asymptomatic dogs. Parasite Immunol 14: 531-539.

27. Badaro R, Jones TC, Carvalho EM, Sampaio D, Reed SG, Barral A, Texeira R, Johnson WD Jr, 1986. New perspectives on a subclinical form of visceral leishmaniasis. $J$ Infect Dis 154: 1003-1011.

28. Alencar JE, 1978. Leishmaniose visceral no Brasil. Rev Med Univ Fed Ceara 17/18: 129-148.

29. Jaffe CL, Keren E, Nahary O, Rachamim N, Schnur L, 1988. Canine visceral leishmaniasis at Wadi Hamam, in Israel. Trans R Soc Trop Med Hyg 82: 852-853. 